\title{
REVISED Case Report: Pulmonary metastases of malignant
}

\section{meningioma [version 2; peer review: 2 approved, 2 approved with reservations]}

\author{
Suhail Basunaid ${ }^{1}$, Frits M.E. Franssen'1, Ryan Accord², Myrurgia Abdul Hamid², \\ Shekar Mahesh4, Brigitta G. Baumert5, Olaf E.M.G. Schijns 6
}

${ }^{1}$ Department of Respiratory Medicine, Maastricht University Medical Centre, Maastricht, 6202 AZ, The Netherlands

2Department of Cardiothoracic Surgery, Maastricht University Medical Centre, Maastricht, 6202 AZ, The Netherlands

${ }^{3}$ Department of Pathology, Maastricht University Medical Centre, Maastricht, 6202 AZ, The Netherlands

${ }^{4}$ Department of Radiology, Maastricht University Medical Centre, Maastricht, 6202 AZ, The Netherlands

${ }^{5}$ Department of Radiation-Oncology (MAASTRO), GROW (School of oncology), Maastricht University Medical Centre, Maastricht, 6202

$A Z$, The Netherlands

${ }^{6}$ Department of Neurosurgery, Maastricht University Medical Centre, Maastricht, 6202 AZ, The Netherlands

V2 First published: 21 Oct 2013, 2:222

https://doi.org/10.12688/f1000research.2-222.v1

Latest published: 29 Aug 2014, 2:222

https://doi.org/10.12688/f1000research.2-222.v2

\section{Abstract}

Meningioma accounts for approximately one-third of primary central nervous system tumors. Most meningiomas are benign, although up to one third are classified as atypical or malignant. We describe a 63year Caucasian male presenting with pleural metastases from an intracranial meningioma. Distant metastases from meningiomas are infrequently found in clinical practice and mostly are associated with atypical or malignant meningiomas. There is no standard treatment; however surgical resection of both the primary and metastatic lesions is the safest therapy. The overall prognosis of atypical meningiomas is poor. Our patient died one week after discharge from our hospital.

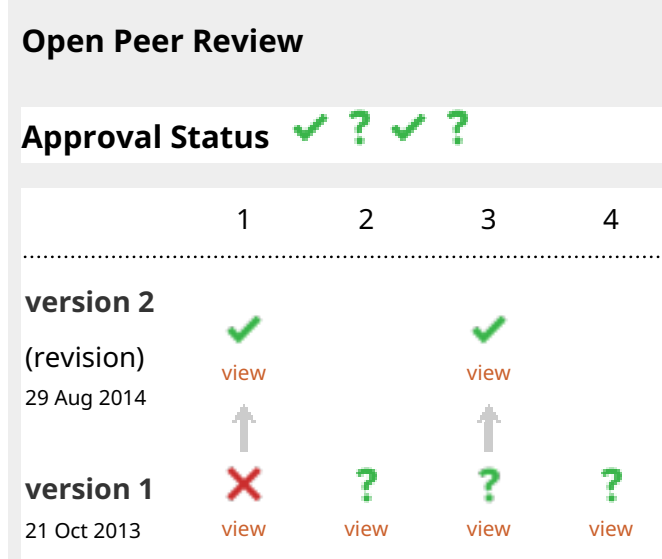

1. Daniel Vorobiof, Sandton Oncology Centre, Johannesburg, South Africa

2. Matthias Simon, University of Bonn, Bonn, Germany

3. Christine Marosi, Medical University of Vienna, Vienna, Austria

4. Antonio Santacroce, Heinrich Heine University, Dusseldorf, Germany Any reports and responses or comments on the article can be found at the end of the article. 
Corresponding author: Suhail Basunaid (s.basunaid@mumc.nl)

Competing interests: No competing interests were disclosed.

Grant information: The author(s) declared that no grants were involved in supporting this work.

Copyright: (c) 2014 Basunaid S et al. This is an open access article distributed under the terms of the Creative Commons Attribution License, which permits unrestricted use, distribution, and reproduction in any medium, provided the original work is properly cited. Data associated with the article are available under the terms of the Creative Commons Zero "No rights reserved" data waiver (CC0 1.0 Public domain dedication).

How to cite this article: Basunaid S, Franssen FME, Accord R et al. Case Report: Pulmonary metastases of malignant meningioma [version 2; peer review: 2 approved, 2 approved with reservations] F1000Research 2014, 2:222

https://doi.org/10.12688/f1000research.2-222.v2

First published: 21 Oct 2013, 2:222 https://doi.org/10.12688/f1000research.2-222.v1 


\section{REVISED Amendments from Version 1}

We have revised the article text of the case report and discussion and taken the comments of the referees into account.

See referee reports

\section{Case report}

A 63-year-old Caucasian man was referred to our hospital for further analysis of slowly progressing pleural effusion with a history of cough and dyspnea. The patient had a long history of epilepsy and meningioma. He was working as head in a department of administration. He was married and had two healthy kids. As a medication he took Pantoprazol, Tegretol and Dorsolamide and had stopped smoking a long time ago.

Our patient was diagnosed with progression of a previous operated (Simpsom ${ }^{3}$ resection) and postoperatively irradiated (30 x $2 \mathrm{GY}$ with a total doses of 60 Gy within the EORTC 22042 in a study context) atypical left parieto-occipital meningioma (WHO grade-II). Re-resection of the tumor ( Simpsom $^{4}$ ) was performed and histopathology showed a malignant meningioma (WHO grade-III). In the follow up after re-resection there was an obvious evidence of a residual tumour at the falx cerebri. One year later an asymptomatic re-recurrence was diagnosed (Figure $1 \mathrm{~A}$ and $\mathrm{B}$ ), for which conservative follow-up was performed without further surgical intervention. This was given in the form of re-irradiation with a total doses of 130 Gy (60 Gy given for the re-re-recurrent tumor at the resected area + additional $70 \mathrm{GY}$ applied as an integrated boost with IMRT-technic for the residual tumor at the falx cerebri). This decision was taken due to the higher degree of aggressiveness of the malignant meningioma, as further surgical intervention would harm the patient rather than curing him.

A few months later the patient was hospitalized with dyspnea, fatigue, productive cough and anorexia. Multiple pleural masses were detected at a chest computer-tomography (CT) scan. Histopathology

A

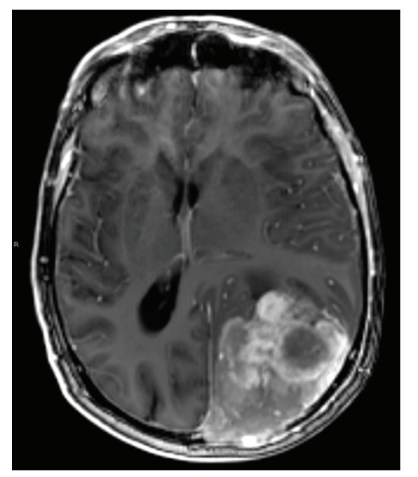

B

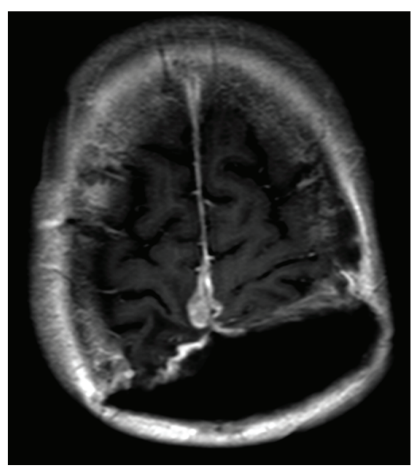

was consistent with malignant meningioma (WHO grade-III, Figure 2A), there was a high expression in the EMA staining, also in the AE1/AE3 staining (Figure 2B). The CD 45 and CD 68 were positive and MIB-1 showed high proliferation. Palliative chemotherapy was offered but refused by the patient. The patient is died one week after discharge from the hospital as a result of voluntary euthanasia as was the will of the patient (valid written declaration).

\section{Discussion}

Pulmonary and pleural metastases from an intracranial meningioma are very rare. Distant metastases from meningiomas are infrequently found in clinical practice and mostly associated with atypical or malignant meningiomas. Meningiomas mainly recur loco-regional or adjacent to the radiation treatment fields ${ }^{1,2}$. There are only isolated case reports regarding pulmonary metastases from meningioma. Most lung metastases were incidentally detected by chest radiography or by CT-scans, because metastatic lesions are usually asymptomatic. The presence of pulmonary metastases appears to negatively affect survival in patients with recurrent meningioma ${ }^{3,4}$.

Regarding the relationship between the intracranial location and invasion of the sagittal sinus of the tumor and the pleural metastases the route of dissemination is most probably the central venous route to heart and lungs ${ }^{5}$. In previous case reports the lung was the most common extracranial metastatic site for intracranial meningioma ${ }^{6}$. Our case was unusual because of the highly rate of recurrences and later the distant metastases. There is no standard treatment in the case of distant metastases.

In this case, histopathologic findings of the primary tumor revealed hypercellularity, wide necrosis, and brain invasion into the normal brain parenchyma. Pathology of the lesion from the left thoracic wall was consistent with malignant meningioma.

Other case studies described that treatment of pulmonary metastasis of malignant meningioma consisted of surgical resection for both the primary or metastatic lesions ${ }^{1,5,7}$.

C

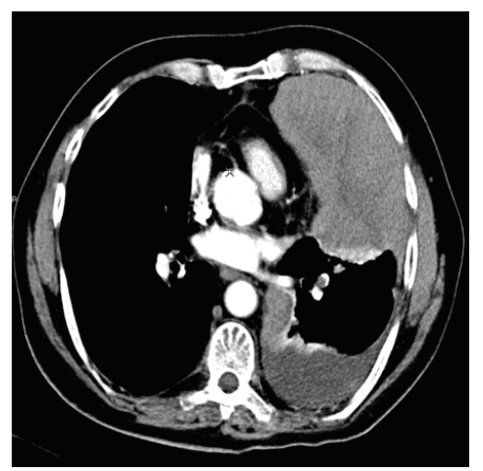

Figure 1. MRI and CT scanning of the original meninigioma intra-cerebral and at distance metastasis intra-pleural. A: T1 weighted image after administration of Gadolinium based contrast fluid shows a large extra-axial enhancing lesion in the left parieto-occipital region with local mass effect. Note that the sagittal sinus seems to be invaded. B: Contrast enhanced T1 weighted image after administration of Gadolinium based contrast fluid showing a large resection cavity after the second operation and recurrent disease at the most upper margin of the resection plane with enhancing areas surrounding the sagittal sinus. C: Midthoracal CT slice in the transverse plane. Scan performed after i.v. administration of iodine contrast. The lesion is easily distinguished at the left ventral thoracal intrapleural space, slightly enhanced suggesting solid tissue. Some pleural fluid is also present. 
A

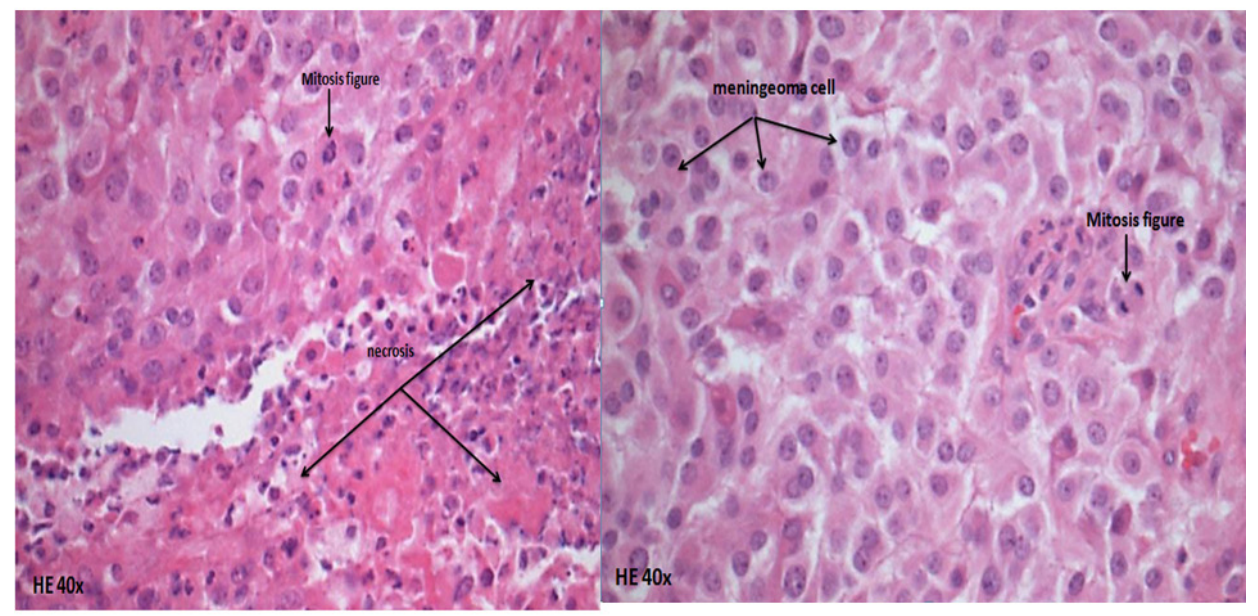

B

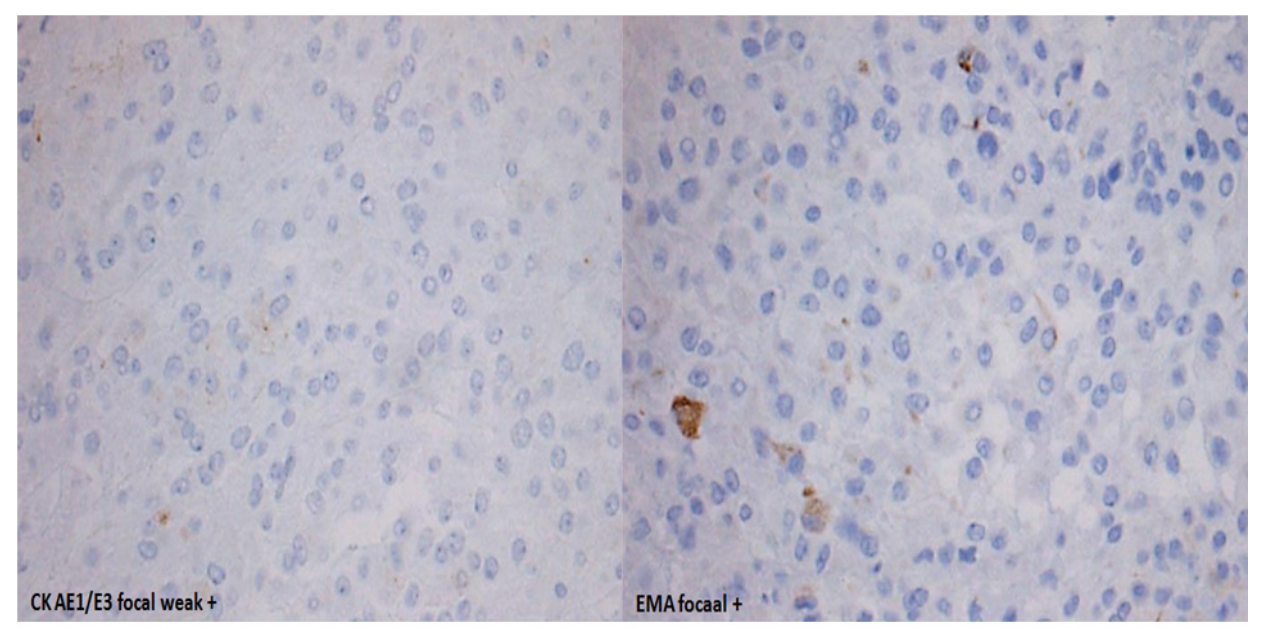

Figure 2. Histology staining of a biopsy of the solid intrathoracal lesion showing the same morphology as the intracranial meningioma. A: A specimen (HE-stained, 40x) showing histological resemblance between the intrathoracal lesion and the intracranial meningioma. B: Specimen (focal plus and focal weak) showed high expression in the EMA-staining and also in the AE1/AE3-staining.

Postoperative conventional radiation therapy has been recommended for prevention of local recurrence, especially when resection is subtotal. There are insufficient data regarding radiation therapy by meningiomas with distant metastases, palliative chemotherapy is the only option in the case of distant metastases, however data regarding the efficacy of this systemic treatment are unknown.

\section{Informed consent}

Written informed consent for publication of clinical details and clinical images was obtained from the next of kin.

\section{Author contributions}

Frits Franssen: supervisor of the respiratory department where patient was admitted. Ryan Accord: the surgeon who did the VATS.
Myurgia A. Hamid: histological figures. Shekar Mahesh: radiological figures. Brigitta G. Baumert and Olaf E.M.G. Schijns: literature search and data collection.

\section{Competing interests}

No competing interests were disclosed.

\section{Grant information}

The author(s) declared that no grants were involved in supporting this work.

\section{Acknowledgments}

At the completion of this Case study, I am very thankful to all contributors, who were very helpful and without their support this case study would have never come into its present form. 
1. Figueroa BE, Quint DJ, Mckeever PE: Extracranial metastatic meningioma. Br J Radiol. 1999; 72(857): 513-516.

PubMed Abstract | Publisher Full Text

2. Stoller JK, Kavuru M, Mehta AC: Intracranial meningioma metastatic to the lung Cleve Clin J Med. 1987; 54(6): 521-526. PubMed Abstract | Publisher Full Text

3. Alexandru D, Glantz MJ, Kim L: Pulmonary metastases in patients with recurrent, treatment-resistant meningioma: prognosis and identification by ${ }^{111}$ Indiumoctreotide imaging. Cancer. 2011; 117(19): 4506-11. PubMed Abstract | Publisher Full Text

4. Enam SA, Abdulrauf S, Mehta B: Metastasis in meningioma. Acta Neurochir (Wien). 1996; 138(10): 1172-7.

PubMed Abstract | Publisher Full Text
5. Nakano M, Tanaka T, Nakamura A: Multiple Pulmonary Metastases following total removal of a bilateral parasagittal meningioma with complete occlusion of the superior sagittal sinus: Report of a Case. Hindawi Publishing Corporation. Case Rep Neurol Med. 2012; 2012: 7.

PubMed Abstract | Publisher Full Text | Free Full Text

6. Strang RR, Tovi D, Nordenstam H: Meningioma with intracerebral, cerebellar and visceral metastases. J Neurosurg. 1964; 21(12): 1098-1102.

PubMed Abstract | Publisher Full Text

7. Kanzaki R, Higashiyama M, Fujiwara A: Surgical resection of pulmonary metastases from meningioma: report of a case. Surg Today. 2011; 41(7): 955-8.

PubMed Abstract | Publisher Full Text 


\section{Open Peer Review}

\section{Current Peer Review Status:}

\section{Version 2}

Reviewer Report 17 September 2014

https://doi.org/10.5256/f1000research.5568.r6157

(C) 2014 Marosi C. This is an open access peer review report distributed under the terms of the Creative Commons Attribution License, which permits unrestricted use, distribution, and reproduction in any medium, provided the original work is properly cited.

\section{Christine Marosi}

Department of Oncology, Medical University of Vienna, Vienna, Austria

The authors added valuable information on the radiotherapy in relapse as requested, so there is one question remaining for me: was an intracranial relapse diagnosed after reirradiation? However I feel confident in approving the version 2.

Competing Interests: No competing interests were disclosed.

\section{I confirm that I have read this submission and believe that I have an appropriate level of expertise to confirm that it is of an acceptable scientific standard.}

Author Response 23 Sep 2014

Suhail Basunaid, Mayo University Hospital,, Ireland

Dear Christine Marosi

Thank you very much for your approval

Suhail

Competing Interests: no competing interests were disclosed.

Reviewer Report 10 September 2014

https://doi.org/10.5256/f1000research.5568.r6093

(c) 2014 Vorobiof D. This is an open access peer review report distributed under the terms of the Creative Commons Attribution License, which permits unrestricted use, distribution, and reproduction in any medium, provided the original work is properly cited. 


\section{Daniel Vorobiof}

Department of Medical Oncology, Sandton Oncology Centre, Johannesburg, South Africa

The authors have acted on the suggestions of the reviewers and improved the description of the case. The report adds to the list of uncommon spread sites from a malignant neurological tumor.

Competing Interests: No competing interests were disclosed.

\section{I confirm that I have read this submission and believe that I have an appropriate level of expertise to confirm that it is of an acceptable scientific standard.}

Author Response 23 Sep 2014

Suhail Basunaid, Mayo University Hospital,, Ireland

Dear Daniel Vorobiof

Many thanks for your approval.

Suhail

Competing Interests: no competing interests were disclosed.

\section{Version 1}

Reviewer Report 21 August 2014

\section{https://doi.org/10.5256/f1000research.2443.r5747}

(C) 2014 Santacroce A. This is an open access peer review report distributed under the terms of the Creative Commons Attribution License, which permits unrestricted use, distribution, and reproduction in any medium, provided the original work is properly cited.

\section{Antonio Santacroce}

Department of Neurosurgery, Heinrich Heine University, Dusseldorf, Germany

Basunaid et al. report on a patient harboring a recurrent meningioma who developed pleural metastases. The primary tumour is reported to be an atypical meningioma WHO Gr II, which upon recurrence shows a malignant histology WHO Gr. III.

I share the opinion of Drs Marosi and Simon about the importance of continuing reporting such clinical cases due to the rarity of such tumour entities, even though, as reported by Dr Vorobiof "It doesn't add any further information and doesn't contribute any new knowledge, neither diagnostic nor therapeutic to the current available medical literature" 
There are some points which should be clarified. To quote the authors:

"Our patient was diagnosed with progression of a previous operated and irradiated (60 GY) atypical left parieto-occipital meningioma (WHO grade-II). Re-resection of the tumor was performed and histopathology showed a malignant meningioma (WHO grade- III). After reoperation, re-irradiation (60GY + additional 70GY) was given."

Which radiation technique was used? It is not clear whether the radiation dose applied upon recurrence was only 60Gy with the boost, and if the "additional" $70 \mathrm{~Gy}$ is the cumulative dosage applied including the boost, or just the boost itself.

I would also recommend verifying in the literature whether radiation therapy has been offered for histologically confirmed metastatic extracranial lesions.

Competing Interests: No competing interests were disclosed.

I confirm that I have read this submission and believe that I have an appropriate level of expertise to confirm that it is of an acceptable scientific standard, however I have significant reservations, as outlined above.

Reviewer Report 27 June 2014

https://doi.org/10.5256/f1000research.2443.r5253

(C) 2014 Marosi C. This is an open access peer review report distributed under the terms of the Creative Commons Attribution License, which permits unrestricted use, distribution, and reproduction in any medium, provided the original work is properly cited.

\section{Christine Marosi}

Department of Oncology, Medical University of Vienna, Vienna, Austria

I fully agree with the reviewer from Bonn, Matthias Simon. Meningiomas grade III are fortunately rare and they do metastasize through vascular pathways. Of course a register of such cases would be a valuable tool to get an idea of the prevalence of such events. The case reported by Basunaid is a tragic one as the patient asked for euthanasia one week after dismissal from hospital. This shows that he could not be offered any therapeutic option able to provide enough solace for staying alive.

Competing Interests: No competing interests were disclosed.

I confirm that I have read this submission and believe that I have an appropriate level of expertise to confirm that it is of an acceptable scientific standard, however I have significant reservations, as outlined above. 
Suhail Basunaid, Mayo University Hospital,, Ireland

I would like to thank Dr. Marosi for her time spent on reviewing this case report, and the valuable comments given. I would like to leave my current version as it is. I completely agree regarding the facts about the rarity of the case and the termination by the euthanasia declaration.

Competing Interests: No competing interests were disclosed.

Reviewer Report 16 January 2014

https://doi.org/10.5256/f1000research.2443.r2861

(C) 2014 Simon M. This is an open access peer review report distributed under the terms of the Creative Commons Attribution License, which permits unrestricted use, distribution, and reproduction in any medium, provided the original work is properly cited.

\section{Matthias Simon \\ Department of Neurology, University of Bonn, Bonn, Germany}

Basunaid et al. describe a patient with a recurrent meningioma who ultimately developed pleural metastases. The primary tumor was assigned to WHO grade II, and the recurrent tumor to grade III. While this paper by itself does not provide truly novel information, in my view such rare patients should be reported in the literature. This and similar reports will help to build a database which may at some point help to improve our understanding and management of rare conditions. The report may benefit from a more comprehensive and detailed (tabular?) review of the literature.

Competing Interests: No competing interests were disclosed.

I confirm that I have read this submission and believe that I have an appropriate level of expertise to confirm that it is of an acceptable scientific standard, however I have significant reservations, as outlined above.

Author Response 27 Jun 2014

Suhail Basunaid, Mayo University Hospital,, Ireland

I would like to thank Dr. Simon for his time and valuable comment. I wish to leave my current version as it is.

Competing Interests: No competing interests were disclosed. 


\section{https://doi.org/10.5256/f1000research.2443.r2143}

(C) 2013 Vorobiof D. This is an open access peer review report distributed under the terms of the Creative Commons Attribution License, which permits unrestricted use, distribution, and reproduction in any medium, provided the original work is properly cited.

\section{Daniel Vorobiof}

Department of Medical Oncology, Sandton Oncology Centre, Johannesburg, South Africa

This case report documents an unusual spread of a malignant meningioma. It doesn't add any further information and doesn't contribute any new knowledge, neither diagnostic nor therapeutic to the current available medical literature.

Competing Interests: No competing interests were disclosed.

I confirm that I have read this submission and believe that I have an appropriate level of expertise to state that I do not consider it to be of an acceptable scientific standard, for reasons outlined above.

Reader Comment 06 Jun 2014

Suhail Basunaid, Mayo University Hospital,, Ireland

Dear Sir,

I am not sure if you consider this an unusual spread of malignant meningioma. There were at least 3 years between the time of discovering it (by accident after a fall from his bicycle) and the pulmonary involvement. I can understand that this case report might not be a unique case but I found myself obliged to report it. There is not enough knowledge in the literature regarding the therapeutic options for malignant meningioma with distance metastases. There was a declaration of euthanasia by our patient but things went too quickly and our patient died shortly after discharge before being able to make an accurate decision.

Competing Interests: No competing interests were disclosed. 
The benefits of publishing with F1000Research:

- Your article is published within days, with no editorial bias

- You can publish traditional articles, null/negative results, case reports, data notes and more

- The peer review process is transparent and collaborative

- Your article is indexed in PubMed after passing peer review

- Dedicated customer support at every stage

For pre-submission enquiries, contact research@f1000.com 